\title{
Patente gera patente?
}

\section{Does the patent develop patent?}

Joana Coeli Ribeiro GARCIA

\author{
RESUMO
}

A patente, fonte de informação e geradora de nova patente em condições e contexto favoráveis, constitui objeto desta pesquisa. Esta é respaldada em quadro teórico da Ciência da Informação e identifica os fatores intervenientes no fluxo das relações desde a patente-fonte até o registro de nova patente. Da amostra da pesquisa constam instituições privadas e públicas representadas por unidades situadas em Brasília, Belo Horizonte e Rio de Janeiro. A entrevista é a técnica usada para a coleta de dados, e estes são analisados por meio de categorias. Os resultados foram obtidos através de comparações entre o modelo teórico (ideal) e o real, apreendido a partir da análise dos depoimentos dos entrevistados. Conclui-se que o fluxo sofre múltiplas intervenções (por parte do governo, das instituições públicas de ensino e de pesquisa, das instituições privadas, do sistema de patentes e do mercado), e que, no âmbito do Brasil, a patente não se apresenta como informação necessária para a produção de tecnologia e de inovação. A real transferência e transformação da patente em conhecimento, exige que a sociedade brasileira ultrapasse a fase das políticas e dos discursos de intenção, para a fase das ações realizadas de forma coordenada entre os atores, de forma a induzir os agentes a investir, atendendo às necessidades da sociedade.

Palavras-chave: informação científica e tecnológica; patente; gestão de ciência e tecnologia; transferência de tecnologia.

\begin{abstract}
A B STRACT
The patent as a source of information which might generate new patents on favorable circumstances and context is the object of this research. Supported by theoretical framework of the Information Science, this study identifies the factors/agents intervening in the Brazilian patent process, ie, the relations flow from patent-as-information-source and production-element of new knowledge, to the obtaining of a new patent. The research sample is constituted by public and private institutions, represented by education and research units located in Brasilia, Belo Horizonte and Rio de Janeiro. The interview is the method used for data collection; and the results are analyzed by categories.. The results were obtained by comparisons between the theoretical (ideal) model and the real model, the latter was drawn from the statements found in the research subjects' interviews, therefore, from their professional experience. It was found that government, educational, and research institutions, public and private as well, besides the Brazilian patents' system and the economic market, all exert substantial interference on the patent flow. The results allow the conclusion that, in Brazil, the patent is not currently perceived as necessary information in order to produce technology and innovation. Thus, in order to reach the real transference and transformation of patent/information into new knowledge, Brazilian society needs to go beyond the current politics of intent discourse, to a new political phase. This phase should be one of actions to be accomplished through the coordination among actors with common objectives; these should be such to induce investors into taking into consideration the society needs.
\end{abstract}

Key words: Scientific and technological information; patent; scientific and technological management; technology transference.

\footnotetext{
1 Professora Doutora, Departamento de Biblioteconomia e Documentação, Centro de Ciências Sociais Aplicadas, Universidade Federal da Paraíba. Campus I, Cidade Universitária, Castelo Branco, 58090-190, João Pessoa, PB, Brasil. E-mail: <joanacoeli@uol.com.br>. Recebido em 24/4/2006 e aceito para publicação em 4/9/2006.
} 


\section{N T R O D Ç Ã O}

A partir de 1980, o entendimento de que informação e conhecimento têm relação de proximidade está mais disseminado do que em épocas anteriores. Grandes quantidades de informação provocam transformações em setores individuais e coletivos e tornam-se eixos da globalização. Áreas diversas como Sociologia do Conhecimento, Economia da Informação ou do Conhecimento visam à transmissão de informações e geração de conhecimento, e a Ciência da Informação $(\mathrm{Cl})$ focaliza em seus estudos o fluxo de informação em cujas extremidades situam-se os dois elementos. A Cl se ocupa ainda do conhecimento interativo que modifica as relações do emissor, dos estoques de informação e dos receptores no tempo e no espaço (BARRETO, 2002). Entretanto somente a possibilidade de dispor de informação não é suficiente para adquirir conhecimentos, pois a ambiência em que o indivíduo se encontra contribui ou dificulta o atendimento ao "estágio melhor" (BARRETO, 1998) que o conhecimento proporciona.

A patente é um documento, fonte por excelência da informação tecnológica, que oferece vantagens indispensáveis para geração de novas tecnologias. É propriedade intelectual, que concede a alguém o direito de uso exclusivo, durante certo período, de algo por ele criado ou aperfeiçoado. É privilégio concedido pelo Estado para exploração comercial do objeto da patente, por tempo determinado, beneficiando o inventor e a sociedade.

Dentre as vantagens, considera-se o sistema de patentes, o qual determina sua distribuição e potencializa a produção do conhecimento. Porém, como nos demais sistemas, as informações sofrem seleção ao se definir o que constitui propriedade industrial e inserção no estoque; por sua vez os receptores escolhem informações de acordo com suas demandas. O processo para disponibilizar informações resulta de interferências ideológicas, culturais, semânticas e contextuais, por meio das políticas, às quais se vinculam às necessidades dos usuários. $A$ escolha dos canais de transferência das informações e dos instrumentos de representação também é ato político. Juntas ou per se determinam o uso ou não, o descarte e a absorção da informação.

A assimilação da informação tecnológica pressupõe a disseminação tanto do produto quanto do subproduto, esse entendido como documento de patente. Ao fluir, a patente estabelece relações, favoráveis ou não, para gerar nova tecnologia patenteável. Essas condições dizem respeito à ação da informação e seus espaços de interação entre os atores, nos quais o diálogo se estabelece entre os agentes e os espaços de provisão dos estoques, interno e externo, com destaque para direção, superação das tensões, motivação, e intenção, na opinião de Wersig e Windel (1985).

São fatores que interferem no sistema que disponibiliza as patentes, como também nas instituições de ensino e pesquisa, nos departamentos de pesquisa e desenvolvimento (P\&D) e nas demais instituições que usam a patente como informação para gerar conhecimento. Ademais, interferem no ambiente interno do país e na competência instalada para uso do conhecimento aplicável para transformá-lo em produto ou processo. Considerando aspectos estruturais, conjunturais e contextuais que a globalização e o uso das tecnologias de informação e comunicação (TICs) possibilitam à patente, o estudo verifica se a informação (patente) transforma-se em conhecimento (tecnologia registrada em patente) nas atuais condições brasileiras.

\section{MODELO TEÓRICO}

A pesquisa é o modo eficaz de se chegar ao conhecimento para o qual há que utilizar as informações disponíveis e acionar o Sistema Brasileiro de Ciência e Tecnologia - composto por órgãos, instituições e empresas -, que qualifica pessoal, realiza pesquisa, amplia, absorve e avalia conhecimentos decisivos na produção de produtos, processos e serviços para a sociedade. Ainda assim, acessar um estoque não necessariamente é usá-lo realmente, usá-lo com eficiência ou usá-lo em sua totalidade.

Wersig (1993) referem-se a esse aspecto ao afirmar que solucionar um problema pode significar redefinir e encontrar estratégia de ação mais simples como recuperar fragmentos internalizados de conhecimento que não afloram conscientemente, mas influenciam na solução. O processo de inovação inicia com uma idéia, simples ou complexa, introduz novidade na tecnologia a partir da experiência ou da intuição do inventor ou com base em pesquisa científica. Se conhecimento é o "conjunto de informações 
que, absorvidas ou assimiladas, é capaz de modificar a estrutura cognitiva do indivíduo, do grupo ou da sociedade" (BARRETO, 1992, p.12), tecnologia é conhecimento - científico, empírico ou intuitivo - absorvido e assimilado, que contribui, impulsiona e atua determinando o grau de desenvolvimento científico, econômico e social de uma nação.

Autores como Sábato e Botana (1968) lembram que um país desenvolvido é um país que detém tecnologia, ao passo que a nação que não a possui, e, portanto, a importa de outro, é considerado subdesenvolvido, periférico ou dependente. Para esses autores, a pesquisa científica e tecnológica efetivada de forma sistemática e permanente, por meio de infra-estrutura adequada, que respeita as idéias dos cientistas, gera e atende novas demandas, pode impulsionar o desenvolvimento da América Latina.

O modelo triangular não apenas interpreta as relações entre governo, C\&T e estrutura produtiva, mas assegura a capacidade racional de uma sociedade saber onde e o que inovar. Isto é, permite alcançar os objetivos estratégicos propostos pela sociedade. No vértice superior do triângulo os autores inserem o governo e nos dois vértices da base, universidade e empresa. Cada vértice desenvolve relações de manutenção e organização interna, que denominam de intra-relações, e que objetivam se tornar centros capazes de gerar, incorporar e transformar as demandas em inovação científica e tecnológica. No interior do triângulo cada um dos elementos mantém relações de sentido vertical do governo com a infra-estrutura de C\&T e com a estrutura empresarial. Horizontalmente, estão as interrelações entre universidades e empresas, consideradas como as mais importantes. Por último, vêm as extra-relações que acontecem entre o triângulo ou entre cada um dos vértices com o entorno, a sociedade e o mercado (SÁBATO; BOTANA, 1968).

Ferramenta de transformação da sociedade, a pesquisa pode gerar um conhecimento não imediatamente útil ao setor tecnológico produtivo e ficar à espera de oportunidade de emprego efetivo. Também gera excedente de conhecimento não aplicável ao setor produtivo essencial à ampliação do acervo da ciência. Tal conhecimento retorna ao sistema como informação, recompondo o ciclo de informação permanentemente. Embora a busca da verdade pelo conhecimento seja imprescindível, o processo não deve se encerrar no conhecimento, e sim ir além para gerar riqueza, e ser aplicado na produção de bens e serviços. Situam-se aqui as diferenças culturais entre as instituições. Na academia, prioriza-se o pensar e o agir. Na empresa, a lógica dirige-se ao mercado, encontrando-se na acumulação: a primeira, do conhecimento; e a segunda, do lucro financeiro.

$\mathrm{Na}$ academia, a produtividade é medida pela quantidade de publicação, estabelecendo hierarquia entre autores e universidades. Os de maior prestígio publicam mais que os de menor prestígio, dentro de analogia ao primeiro livro do Novo Testamento escrito por Matheus, estabelecida por Merton (1988) e conhecida como "efeito Matheus" de que aos que mais possuem será dado sempre mais, em oposição aos que menos possuem.

No sistema de estratificação da ciência, os pares dos cientistas e seus associados reconhecem os avanços científicos como prenúncio de novas e grandes descobertas. A atividade científica resulta da interação entre os cientistas e da competição entre eles, e não de uma predisposição inerente. Suas motivações e ações não são isoladas. Deles, mais e mais se espera, criando medidas de motivação e estresse. Os mecanismos responsáveis por tal organização, pela busca de conhecimento e pela tensão em estar constantemente produzindo a que os cientistas são conduzidos, se inspiram em diferentes versões da economia. A primeira, na economia da troca: o cientista que recebe reconhecimento torna-se devedor do colega que devolve com a mesma moeda. No modelo da economia neoclássica, o cientista se compara a um vendedor. O produto oferecido é conhecimento, mais tarde avaliado pelas funções de qualidade e utilidade. Cada cientista é financiado para maximizar o lucro, que se impõe como sua garantia de reconhecimento e gera um clima de competição, como no mercado neoclássico. Outro modelo vem do capitalismo, como descrito pelos marxistas. Os cientistas não somente estão interessados no reconhecimento per se, como na possibilidade de ampliá-lo mais e mais. Para sobreviver, pesquisadores não têm escolha, têm de acumular créditos, constituindo seu capital. Sem isto, não há como financiar projetos. Por outro lado, quanto mais capital, mais conduzem novas pesquisas, aumentando o investimento inicial (CALLON, 1994). 
Merton (1988) insiste no papel de normas institucionalizadas definidoras do comportamento e do sistema de reconhecimento da produção de conhecimento. Sob outro ângulo, a propriedade intelectual constitui paradoxo, pois estabelece substância a algo doado livremente a outros que dela querem fazer uso.

A perspectiva de usar a informação e transformá-la em conhecimento, enfoque da $\mathrm{Cl}$, torna visível a relação com a área da gestão, economia e cognição, dentre outras. Até época recente, havia um pool de empresas partilhando as mesmas informações. Hoje, vários elementos, várias pessoas, vários troncos de empresas ou várias empresas formam redes com o objetivo de realizar algo, contando com a flexibilidade e a adaptação rápida às demandas. A diferença reside em que podem separar-se tão logo atinjam a consecução do objetivo ou continuarem conectadas, escolhendo para coordená-las uma empresa-rede.

Há tendência à interdisciplinaridade formalizada por parcerias profissionais para gerar pesquisas e conhecimentos. Por exemplo, a inteligência tecnológica se junta à negociação da tecnologia, reunindo áreas da economia e do comércio exterior; com a propriedade industrial, a economia e o direito se envolvem; na prospecção tecnológica, atuam engenheiros, que lançam mão da inteligência competitiva, contando com administradores. Algumas dessas profissões e temáticas fazem parte do cotidiano da Cl.

A troca de informações só é comunicada com eficácia a pessoas ou a grupos que detenham, minimamente, conhecimentos sobre o tema em foco, portanto é importante que o setor produtivo passe a ver a informação e o conhecimento dela decorrentes como insumo para sua produção e seu crescimento. A despeito da existência desses sistemas, as empresas monitoram os ambientes interno e externo, mantêm-se informadas das necessidades e tendências do mercado, tomam decisões e ampliam seu nível de competitividade, porque as TICs Ihes possibilitam melhor aparelhamento e gestão do ambiente informacional.

Os aspectos teóricos estudados representam modelo em que a patente é fonte de informação e gera nova tecnologia. $O$ modelo foi submetido à verificação, selecionando-se dentre o universo de
C\&T, instituições acadêmicas e de pesquisa que geram conhecimento, que estimulam sua transformação em produtos e processos, e setores dedicados à gestão tecnológica e à política de propriedade intelectual, vinculados a cinco ministérios. Outras instituições, associações e empresas foram selecionadas por envolvimento com a pesquisa, com a intermediação no registro de patentes, com a produção de tecnologia e por sua relação com a pesquisa científica e tecnológica. As unidades da amostra estão em Belo Horizonte, Brasília e Rio de Janeiro. São influenciadas por políticas governamentais, econômicas e mercadológicas, efetuam pesquisa e produzem conhecimento, distribuem e comercializam tecnologias, promovem e fomentam o desenvolvimento tecnológico, e mediam o registro, atuando, ainda, em questões jurídicas relativas à patente.

\section{A Ç Ã O D A P A T E N T E}

Uma informação pode constituir-se em fonte e ser utilizada na produção de novo conhecimento, inserida em um contexto informacional, formado a partir de outras informações, tais como memórias individuais e coletivas, resultantes de conhecimentos anteriores e atuais. Essas possibilidades formam conjuntos com competência para gerar conhecimentos. Condição para que a afirmativa seja verdadeira é que a informação esteja disponibilizada em ambiente propício que permita ser ela percebida.

O elo formado pelos aspectos teóricos, a partir da triangulação governo, instituições de pesquisa e setor produtivo, a disponibilidade do estoque de informação da patente e o ambiente mercadológico fornecem condições para identificar fatores que interferem nas relações entre agentes e espaços de informação, a seguir analisados.

\section{Fatores relativos ao governo}

Para a patente alimentar a pesquisa como informação, representar a tecnologia e estar disponível para licenciamento é preciso, a princípio, analisar os fatores governamentais. Este é um exemplo de discurso adequado de política pública. As dificuldades aparecem quando se operacionalizam tais políticas, razões pelas quais não estão separadas em 
facilitadoras ou impeditivas do fluxo da patente uma vez que uma mesma política pode ser vista sob ângulos antagônicos, sobretudo quando não efetivada em ação.

Os aspectos institucionais ou normativos estão relacionados a leis relativas à patente, como a Lei n. 9.279, em vigor desde 1996, que disciplina as condições para seu registro e a Lei n. 10.973, de 2004, que objetiva o alcance da autonomia tecnológica do país, estabelecendo medidas de incentivo à inovação e à pesquisa científica, por isso denominada Lei de Inovação. Já a Lei de Licitação n. 8.666, de 1993, não é específica para lidar com bens intangíveis, e por isso afeta a patente de forma indireta porque o autor de uma patente licenciada faz jus a prêmio de até um terço dos royalties recebidos pela empresa cessionária. Assim a empresa paga a licença para utilizar a tecnologia, retirando o percentual que cabe ao autor, provocando relações negativas entre as empresas.

No Brasil há leis que se cumprem e leis que não se cumprem. Embora sejam definidoras de políticas não se efetivam em ações favoráveis a deslanchar o desenvolvimento tecnológico. Por outro lado leis não mudam o modo de vida de uma sociedade, não obrigam, por exemplo, universidades e centros de pesquisa a desenvolverem pesquisas e organizarem cursos direcionados para inovação, nem poderiam fazê-lo. Os cursos são planejados em atendimento a vocações regionais. Pesquisa demanda continuidade; sistematização e recursos são ações que não se concretizam por decreto, portanto leis não proporcionam a estabilidade das pesquisas.

O governo pretende reduzir custos ao licenciar uma patente e deveria saber de antemão se há empresa no país capaz de produzir aquele bem intangível. Já a empresa deveria perceber a oportunidade para atuar, pois do contrário a licença nada adianta. Pesquisa do Instituto Brasileiro de Geografia e Estatística (IBGE) sobre inovação tecnológica considera que $31,5 \%$ das 72 mil indústrias brasileiras com mais de dez empregados investiram em aprimoramento, visando à substituição de processos produtivos obsoletos (INSTITUTO BRASILEIRO..., 2000b). A inovação beneficia somente setores dinâmicos, depreendendo-se que são as grandes empresas que investem e, certamente, as que atendem aos editais. Elas próprias indicam a escassez de financiamento como elemento que torna lenta a execução de determinados projetos e inviabilizam outros. Ora, se a execução do projeto se amplia no tempo, se não há aporte de recursos, como falar em redução dos custos, como fazer a lei ser cumprida por intenção política?

Outro fator interveniente por parte do governo é a regulamentação da provisão de recursos financeiros. Para promover a atividade inventiva, os subsídios governamentais ocupam lugar importante, pois direcionam a atividade inventiva para destinos compatíveis com os interesses da ideologia do poder, coincidentes ou não, com os dos consumidores. Faltam fomento, incentivo e indicação da direção a tomar, isto é, posicionamentos por parte do Estado, para que as empresas deslanchem.

A novidade dentre as políticas de financiamento da pesquisa é que, além da irrigação pelas agências de fomento, a partir de 1997 surgem os fundos setoriais, objetivando estreitar os espaços de relação entre setor acadêmico e empresa. Tendo em vista que a empresa privada não pode receber diretamente recursos governamentais, o governo repassa para a universidade, e a empresa demanda à universidade, contratando os serviços. Com os fundos setoriais, cria-se o Programa Prospectar do Conselho Nacional de Desenvolvimento Científico e Tecnológico (CNPq), consultando os especialistas do país para indicar as tecnologias prioritárias. É estratégia governamental tornar públicas as áreas de pesquisa que demandam avanço, indicando aos pesquisadores tais necessidades e fornecendo fomento oriundo dos fundos setoriais. Outra política consiste nos Fóruns de Competitividade Industrial, programa que visa favorecer a relação entre governo, setor privado, academia e associações de classe. Reúnem interessados com afinidades em determinado setor industrial, com o intuito de discutir problemas, viabilizar e imprimir agilidade às decisões, adotando a metodologia do diálogo entre eles.

Com relação às políticas referentes a recursos humanos, ressaltam-se as executadas pelo CNPq dedicadas ao fomento da pesquisa, e da Coordenação de Aperfeiçoamento de Pessoal de Nível Superior (CAPES), com a finalidade de formar quadros competentes para desempenho das atividades de investigação. As duas agências responsabilizam-se, em grande parte, pela ampliação dos institutos de 
pesquisa e do número de instituições de ensino superior (IES), formadores da estrutura de C\&T. O governo legisla com o intuito de inibir diferenças entre o pessoal alocado em órgãos públicos e entre esses e o setor privado. Isto tem provocado avalanche de aposentadorias e colocado em risco a viabilidade das instituições públicas, visto que a reposição dos quadros não se faz na mesma quantidade. Quem permanece continua a ser avaliado com base em critérios que consideram primordialmente a quantidade de trabalhos publicados, com pontuação mais elevada para a divulgação no estrangeiro. O conhecimento divulgado no exterior possibilita aos países desenvolvidos, com recursos humanos mais qualificados e infra-estrutura de pesquisa, que se antecipem na utilização dos conhecimentos recém-gerados, repondo os estoques de informação e produzindo tecnologia e inovação com rapidez e qualidade indiscutíveis.

Comprovam esses fatores o acervo crescente, ano a ano, do Instituto Nacional de Propriedade Industrial (INPI), diante, sobretudo, do depósito de patentes das indústrias multinacionais químicas e de medicamentos, confirmando que nessas áreas não dispomos de empresas nacionais desenvolvendo tecnologia e patenteando. Não temos sequer como enfrentar a quebra de patentes dos medicamentos contra a síndrome da deficiência imunológica adquirida (AIDS), propalada pelo governo porque o parque industrial brasileiro não tem condições de produzi-los localmente. Por isso, a dependência persiste a despeito da intenção de baratear os custos dos medicamentos, como esclarece o discurso.

O Instituto Brasileiro de Informação em Ciência e Tecnologia (IBICT) e recentemente a CAPES mantêm banco de teses de textos integrais, divulgando resultados de pesquisas. Se existe a possibilidade de gerar tecnologia, registro de patente, o autor informa para não disponibilizar o texto completo e manter o sigilo até a apropriação pelo setor produtivo. Há proposta de rever os projetos tecnológicos não executados, ou seja, ainda não transferidos e absorvidos pelo setor produtivo, mas questiona-se a duplicidade de esforços dos dois órgãos.

Quanto aos aspectos infra-estruturais, há disseminado tacitamente que o governante que assume, objetivando inovar administrativamente, deve realizar algo de forma diferente do antecessor. Os meios são elementos facilitadores de qualquer processo; envolvem equipamentos, pessoas, conhecimento, ciência e tecnologia ao mesmo tempo, e podem constituir-se em impedimentos. Convive-se com duas lógicas. Se elas não se justificam, ao menos explicam o porquê das contradições com as quais nos defrontamos.

\section{Fatores relativos à universidade \& empresa}

Quando da análise das questões referentes às políticas governamentais, algumas objetivam a aproximação das instituições representativas da universidade \& empresa. Referida pela totalidade dos entrevistados, essa relação integra a função primordial do sistema de informação: transferir informação dos produtores aos consumidores, contabilizando-se algumas iniciativas reveladoras.

A dimensão da aproximação física é dada pela valoração ao primeiro passo: da instituição de pesquisa, se dela provém o entrevistado, da empresa, quando nela ele trabalha. Relaciona-se à primeira situação o exemplo de localização do Centro de Pesquisa Leopoldo A. Miguez de Mello (CENPES) da Petrobrás em área circunvizinha à Universidade Federal do Rio de Janeiro. Exemplifica a aproximação ao Instituto Tecnológico da Aeronáutica (ITA), em São José dos Campos, um parque empresarial no seu entorno com parte de seus executivos das empresas proveniente do ITA. O complexo tecnológico é formado pelo Instituto de Fomento e Coordenação Industrial (IFI), Centro de Pesquisa e Desenvolvimento em Telecomunicações (CPqD), Instituto de Aeronáutica e Espaço (IAE) para atividades aeroespaciais e pelo próprio Centro Técnico Aeroespacial (CTA), além do Instituto Nacional de Pesquisas Espaciais (INPE) do Ministério da Ciência e Tecnologia e da Agência Espacial Brasileira (AEB).

As normas legais facilitam ou não a aproximação, e as dificuldades de entendimento dos papéis dessas duas instituições geram atritos no processo. Além das culturas distintas, até pouco tempo atrás havia reação ao fato de a universidade se aproximar da empresa. Alguns discursos demonstram esses resquícios por acreditar numa "universidade pura" para produzir papers,qualificar pessoal pela graduação e pós-graduação nas diversas áreas, conside- 
rando a interação com a empresa um passo complexo. A Lei de Inovação é uma proposta de remoção dos obstáculos para a produção de tecnologia e inovação, aproximando pesquisadores de setores públicos às empresas privadas.

Parte das políticas relacionadas a instituições de ensino e de pesquisa dirigidas a recursos humanos foi analisada no item anterior. São elas que formam recursos humanos e produzem conhecimento não necessariamente para que a descoberta de um processo gere inovação ou para que o conjunto de informações tenha aplicabilidade. A maioria é cultuada exatamente por conta da cultura acadêmica centrada no pesquisador, definindo o objeto de pesquisa, o método científico utilizado, a aplicabilidade da pesquisa, preocupado em gerar documento, livro, artigo científico. Há identificadas algumas universidades que trabalham pensando em proteger, comercializar, transferir e licenciar o conhecimento, lutando contra as resistências para convencer o pesquisador a primeiro proteger os resultados da sua pesquisa e somente depois conceder acesso.

A produtividade consiste numa relação entre tempo e produção. No processo de avaliação, a publicação científica é estimulada e mais valorada quando a divulgação ocorre no exterior. A patente, ao contrário, além de não poder ser de imediato protegida no exterior, sua concessão em território brasileiro é demorada. Além disso, justificar perante os comitês de avaliação que uma solicitação foi feita demanda algumas providências, como verificar anterioridade e novidade, analisar o mérito, além de outros fatores. Enfim, há sistemas diversos, pois o processo avaliativo da patente não é realizado por pares.

Mesmo onde o conhecimento está sendo gerado e a proteção incentivada, o número de patentes depositadas é ínfimo. A cultura da patente não é difundida amplamente, apesar dos esforços para implantar núcleos descentralizados de estímulo à propriedade industrial nos institutos de pesquisa $\mathrm{e}$ nas universidades. $O$ incremento das inovações viria pela aproximação de pesquisadores com empresas da iniciativa privada, possibilitando a convivência com outras experiências, culturas diferentes, conhecimento das demandas da empresa e do mercado, utilização da experiência de linhas de montagem de produtos, convergindo, então, para uma relação universidadeempresa fluída e sem atritos.
Outros fatores são requeridos para que essa relação aconteça e dê início a uma total mudança. As empresas produtoras de tecnologia desejam utilizar a ciência para melhorar a qualidade, a eficiência de bens e serviços, auferir lucro, diminuir custos e riscos decorrentes das atividades. Os arranjos de cooperação para inovação estabelecem e subdividem responsabilidades entre parceiros que podem ser outras empresas do grupo ou concorrentes, universidades e institutos de pesquisa, clientes, consumidores e fornecedores, empresas de consultoria de capacitação profissional e técnica, isolados ou vários a um só tempo.

Outro elemento facilitador da produção pelo lado da empresa é a consciência tecnológica. Independente do tamanho da empresa, se o profissional tiver responsabilidade tecnológica pode desenvolver tal consciência. Uma empresa necessita de cérebro, pessoas com conhecimento operacional ligadas ao setor de P\&D e de um especialista em gestão de conhecimento para suprir as demandas internas e que esteja atento às necessidades do mercado.

A operacionalização dos critérios de gestão tecnológica entre grandes e pequenas empresas apresenta diferenças. Dados do Instituto Brasileiro..., (2000b) demonstram que pequenas empresas têm menos condições e recursos para acompanhar o desenvolvimento tecnológico à sua disposição, até porque menos recursos geram menos lucratividade. Instituição da esfera pública reclama da inexistência de uma gerência que estabeleça procedimentos institucionais para a geração de conhecimentos, impeça ou chame atenção da comunidade científica para a não publicação de certos trabalhos antes de analisar todas as decisões, verificar questões de sigilo, detectar as pesquisas publicáveis e as patenteáveis e antever possibilidades de empresas ou a de grupo de empresas conceder licenciamento.

Quem investe no setor privado e está requerendo patente são as grandes empresas, que estimulam suas equipes a buscarem soluções tecnológicas para seu nicho de mercado, ocupando-se, algumas vezes, somente em descobrir soluções tecnológicas. Nesse sentido, é importante o estabelecimento de critérios para comercialização. Lógica capitalista de acumulação, a cultura empresarial é própria e em muito difere da instituição pública. Ainda que, na maioria das vezes, a cultura se forme por conhecimento absorvido em cursos ministrados no setor 
público, ela possibilita ao cientista conviver com cultura empresarial e com os desafios do mercado. É uma forma de ampliar os contatos com o universo empresarial. A um ambiente empresarial nascente compete entender a cultura da academia e a lógica da formação de conhecimento, partindo da concepção de que uma idéia pode desenvolver patente. Há experiências positivas em curso relatando a aproximação da empresa com a universidade e de núcleos de tecnologia nas universidades.

O ambiente brasileiro no que respeita à transferência de informações dos estoques de patentes para a geração de conhecimento, entre as instituições de ensino e de pesquisa e o setor produtivo de nova tecnologia e registro de nova patente, se defronta com muitos fatores impeditivos da realização do fluxo. Políticas importam quando há convergência de objetivos e execução de ações que levem à sua consecução.

\section{Fatores relativos ao sistema de patente}

As categorias a seguir complementam análises dos itens anteriores. O sistema brasileiro das patentes é burocrático, além dos dispositivos legais serem utilizados, em grande parte, como instrumento para conceder patentes de invenção $(\mathrm{PI})$ e de modelo de utilidade (MU) em detrimento dos outros tipos. Outros mecanismos podem possibilitar o uso da propriedade industrial por empresas menos favorecidas, mas têm sido descartados por desconhecimento ou por falta de incentivos para colocá-los em prática.

As previsões para o sistema de patentes dos países não desenvolvidos são tenebrosas. Avizinha-se a centralização do sistema da patente mundial, em que Estados Unidos, Europa e Japão aferem a novidade e autorizam a concessão do direito. $O$ discurso utilizado contra os países em desenvolvimento é que os INPI demoram tempo demais para conceder o direito, o que é uma realidade. Há o perigo de que os INPI transformem-se em órgãos carimbadores, o que seria como manter um órgão responsável pela concessão das patentes, mas sem garantir os elementos que constituem sua vantagem.

Quando se fala de tecnologia patenteada, fala-se de tecnologia que pode ser usada no mundo inteiro. Concorrer com uma pesquisa que está sendo realizada nos Estados Unidos, por exemplo, porque será protegida aqui é desleal, pois é uma luta vencida. A gestão do sistema de informação e a indefinição política, reveladores da situação do INPI brasileiro, originam discursos passionais, tendo em vista o descaso e a falta de efetiva utilização de recursos humanos e financeiros para assumir ações, vencer o desconhecimento e os problemas referidos.

As políticas são definidas, vinculadas às instituições internacionais, que exigem funções dos órgãos de propriedade, sem que esses possam atendê-las. É a constatação da divisão do trabalho com a existência dos excluídos e o risco da instituição se transformar num órgão puramente burocrático. A atitude das autoridades revela a pouca importância do Instituto, converte-se em descaso, não se tomam iniciativas, quer para reabilitá-lo, quer para extingui-lo. E o pior: segundo a assunção do relato acima, relega-se o INPI à própria sorte.

\section{Fatores relativos ao mercado}

A globalização da economia, a abertura dos mercados e a concorrência em todas as áreas forçam o mercado brasileiro, a partir dos anos 90, a substituir sua política, ingressando na integração ciência, tecnologia, inovação (C\&T\&I). Isto requer que os atores nacionais estabeleçam relações com o ambiente externo e o contexto internacional, senão em condições iguais, ao menos de proximidade com os países desenvolvidos.

Transformar conhecimento em riqueza é desafio dos países em desenvolvimento. Para se tornarem fortalecidos, uma opção advinda da globalização é a formação de blocos econômicos regionais. $\mathrm{Na}$ América Latina, especialmente no cone sul, já vigora o Mercado Comum do Sul (MERCOSUL) como possibilidade de negociar junto aos países industrializados e minimizar as determinações dos organismos internacionais em prol dos equilíbrios regionais. Os governos dos países assumem o papel de induzir o mercado na direção da política socioeconômica. A prospecção tecnológica determina o que deve ser pesquisado, o que corresponde à indução de mercado, a investimentos e financiamentos de projetos em áreas determinadas.

Nesse ambiente, C\&T\&I são mais importantes agora para elevar o padrão de vida da população e 
consolidar uma economia competitiva. A capacitação nacional em ciência, tecnologia e educação assume grau de importância mais elevado. Ao reconhecermos isso, devemos igualmente reconhecer os desafios a serem enfrentados, além de não descuidarmos das atividades científicas, da inserção maciça da tecnologia como atividade contínua do setor produtivo, da ampliação do parque industrial, com políticas associadas e combinadas para ação efetiva de governo, empresariado, trabalhadores, educadores e cientistas.

Para concretizar o discurso via ação efetiva, a ampliação do acesso e do uso da informação se configura como condição indispensável para assegurar a esses atores a infra-estrutura de conhecimento e informação, com possibilidade de acesso a bases de dados do país e do exterior. O censo demográfico (INSTITUTO BRASILEIRO..., 2000a) apresenta 21 milhões de pessoas com segundo grau concluído. Isto significa pessoal com potencial para concluir a educação formal em termos de graduação e pós- graduação. Ainda que tenhamos nos referido a tecnologia proveniente também do conhecimento empírico e intuitivo, dificilmente a produção decorrente utiliza-se do sistema para patentear suas invenções. Retomamos o censo entendendo que essa seria a população em condições de se apropriar da informação em proveito próprio e também para contribuir com o desenvolvimento de seu espaço de convivência. Em princípio, $12 \%$ da população total com competência cognitiva para assimilar informação e atender aos requisitos das instituições públicas ou privadas não somente necessitam de dispor de melhores condições de vida, educação e saúde, como também necessitam de incentivos e de condições de emprego para que ajudados pela prática possam contribuir com idéias criativas, simples e geradoras de soluções tecnológicas.

A Pesquisa Industrial - Inovação Tecnológica (PINTEC) realizada pelo Instituto Brasileiro..., (2000b) adota metodologia aplicada em vários países, o que possibilita comparabilidade internacional. É uma forma de evidenciar a validade metodológica do trabalho, essencial para conferir confiabilidade. Se esta possibilita a comparação entre países, ressalta as influências do mercado em termos competitivos. Ao referir-se à inovação adotada nas indústrias, considera o que interessa ao mercado nacional e ao mercado internacional. As empresas de maior porte (500 ou mais empregados) indicam a inovação de produto e de processo, enquanto as empresas com 10 a 49 empregados apresentam percentuais menos expressivos e realizam um só tipo de inovação, de produtos ou de processos, isoladamente.

O Instituto Nacional... (2002) emitiu 1944 certificados de averbação de transferência de tecnologia nas diversas categorias (exploração de patentes, uso de marcas, fornecimento de tecnologia). O Brasil situa-se em sétimo lugar entre os dez principais países que fornecem tecnologia. Os Estados Unidos e a Alemanha, com respectivos 565 e 303 certificados, são os primeiros contra 83 brasileiros, isto é, um décimo do fornecimento de tecnologia dos países citados. Os dois juntos representam $45 \%$ do total da tecnologia averbada, em 2002, no Brasil, o que os mantém como parceiros na posição de liderança das indústrias brasileiras no campo tecnológico. As empresas dos estados de São Paulo, Rio de Janeiro e Minas Gerais são demandantes desses contratos, perfazendo $54 \%$ do total de 1944 em oposição a 31 empresas estrangeiras. Com base nesses dados reafirmamos que utilizamos tecnologia dos países desenvolvidos porque eles dispõem de condições para gerar tecnologia, utilizar idéias de outras nações para inovar, ampliar o número de patentes registradas e de transferir informações e conhecimentos.

A utilização de P\&D nas empresas brasileiras é inversamente proporcional ao seu tamanho e diretamente proporcional ao investimento. Maior número de empresas que desenvolvem atividades de P\&D está entre aquelas que têm menos empregados, nas quais os investimentos são menores. Já as grandes empresas, com menor número de atividades de $P \& D$, são as que despendem mais recursos financeiros, ainda segundo o Instituto Brasileiro..., (2000b). Daí se pode inferir que as grandes empresas estão executando pesquisas de maior vulto por imposições mercadológicas.

O segredo de negócio, na maioria das vezes, não é transferido. Ao nos referirmos à transferência de tecnologia, a consideramos sob as denominações de "pseudotransferência" ou de "transferência horizontal", exatamente em virtude do não repasse do conhecimento tácito porque contraria o princípio da patente. A patente é um trade off. A sociedade concede o monopólio em troca da publicação.

A pesquisa sobre inovação tecnológica, realizada pelo Instituto Brasileiro..., (2000b), reforça que as fontes especializadas e institucionais são as menos 
citadas como tendo importância no processo de absorção de informações. A aquisição de P\&D e de conhecimento externos à empresa situa-se, também, entre reduzidos percentuais. Há, também, um número menor de empresas que realizam contratos para a aquisição de licenças, utilizam patentes e know how de universidades e de institutos de pesquisa como fontes de informação.

Autilização de patentes por meio do Programa de Fornecimento Automático de Informação Tecnológica (PROFINT) do INPI é ínfima. Se considerarmos as cem empresas que têm contratos firmados para o recebimento de cópias de folhas de rosto de patentes em confronto a 72 mil empresas industriais com mais de dez empregados no Brasil, temos o percentual de apenas $0,13 \%$.

Outro aspecto ao qual também já nos referimos e que interfere na transferência de informações e de tecnologia para o setor produtivo diz respeito à concentração nas instituições de ensino e de pesquisa do pessoal com qualificação e competência para gerar tecnologia. Essa distribuição desigual de recursos humanos amplia-se ante as dificuldades do setor privado em saber o que está sendo gerado, onde e como acessar.

É um discurso que admite a impotência das ações. No entanto, havendo condições para diagnóstico, o primeiro passo está dado na direção da tomada de decisão e do estabelecimento dos objetivos. Decreta-se a (in)tensão. Isto posto, é coordenar, conduzir e concentrar esforços para a realização das ações. Há que se requisitar os atores interessados e envolvidos (da sociedade civil, do setor produtivo, das instituições de ensino e pesquisa, das agências de fomento) para atuarem em prol da consecução dos objetivos. Regra muito simples. Porém nos faz retornar ao início, detectar os fatores impeditivos e buscar transpô-los, sem esquecer que antes de uma ação se efetivar, ela é mero discurso. E só se efetiva pela relação com outros atores, sejam individuais, coletivos, sejam metainformacionais. É como se, em termos tecnológicos, estivéssemos propondo a reinvenção da roda.

\section{A RODA QUE, NO BRASIL, $N \tilde{A} O R O D A$}

Os resultados apreendidos dos depoimentos dos entrevistados fornecem condições para afirmar que fazer tecnologia não é fazer ciência. Existem diferenças de características e de processamento técnico entre a informação científica e a tecnológica. Diferenças entre as culturas das instituições de ensino e de pesquisa e a cultura desenvolvida nas unidades de produção das empresas. Enquanto para a área científica a publicação é o ápice da pesquisa, para a tecnológica esta é conseguida com a disponibilidade e a aceitação do produto.

Há diferenças no uso que as empresas fazem da propriedade industrial. Em algumas, a divulgação do conhecimento ocorre via patente. Elas o utilizam como elemento estratégico para manutenção do monopólio da tecnologia que produzem. Outras a utilizam para financiar de novo e ampliar as pesquisas por meio da reversão do investimento inicial. No extremo inferior do fluxo de informação, a patente, representação de conhecimento, reinicia o ciclo, porquanto retorna aos estoques na condição de nova informação, ampliando a oferta de informação e mantendo a permanência do fluxo. Na criação dos sistemas de informação e em sua transferência, a lógica adotada é a mesma: oferta-se e aguarda-se a demanda.

Ainda que os acordos realizados tornem a patente documento integrante de um sistema transnacional, as conclusões apresentadas restringem-se a um território. No âmbito do Brasil, a patente, paradoxalmente, não atua como fonte de informação, embora seja considerada e reafirmada como fonte de informação imprescindível para definição antecipada da pesquisa tecnológica. Os bancos de patente não são utilizados em igualdade com os centros de documentação, bibliotecas virtuais ou não. Em outras palavras, o potencial da patente não é explorado, perde-se tempo e dinheiro com pesquisas que gerariam produtos e processos por não verificar a priori se o conhecimento é novo.

Também não é suficiente existir patente, manter um sistema que colete, trate, disponibilize, possibilite acesso e transfira, para que ela seja utilizada. Informação gera informação quando percebida. Quando a necessidade não é sentida, pode ser despertada por um modo ativo de ação existente no espaço de provisão dos estoques de informação. Mas o sistema de patentes não é suficiente para promover a criação de tecnologia: somente contribui para promover tecnologia. 
O fluxo sofre intervenções positivas e negativas por parte do governo, das instituições públicas de ensino e de pesquisa, das instituições privadas, do sistema de patentes e do mercado. No Brasil, a patente não constitui informação necessária para produzir tecnologia e inovação. Outras informações tecnológicas (de fornecedores de equipamentos e matéria prima, de clientes e de concorrentes) são mais úteis e mais utilizadas do que as informações contidas nas patentes. Tais informações, disponibilizadas ou não em suporte físico, são usadas tanto quanto o conhecimento tácito e o empírico na produção de tecnologia.

Para a informação atingir sua real transferência e transformar-se em conhecimento é preciso ultrapassar a fase das políticas e seus discursos de intenção, e adiantar-se para a fase das ações realizadas de forma coordenada entre os atores com objetivos comuns, induzindo os agentes a investir e a atender as necessidades da sociedade. As experiências que se iniciam em vários setores sinalizam avanço. Porém não possibilitam ao Brasil o salto tecnológico. Os avanços sinalizados pelas novas experiências não são suficientes para que as atividades de inovação e tecnologia sejam consideradas consolidadas e para que o país alcance o salto que almeja em direção ao desenvolvimento.

\section{REFERÊNCIAS}

BARRETO, A.A. Informação e transferência de tecnologia: mecanismos e absorção de novas tecnologias. Brasília: IBICT, 1992.

BARRETO, A.A. O rumor do conhecimento. São Paulo em Perspectiva, São Paulo, v.12, n.4, p.69-77, 1998.

BARRETO, A.A. A condição da informação. São Paulo em Perspectiva, São Paulo, v.16, n.3, pt.1, p. 67-74, 2002.

CALLON, M. Four models for the dynamics of science. In: PETERSEN, J.C.; MARLDE, GE.; JASANOFF, S.; PINCH, T. (Ed.). Handbook of science, technology and society. Newbury Park, CA: Sage, 1994.

INSTITUTOBRASILEIRODEGEOGRAFIAEESTATÍSTICA. Censo 2000a. Resultados da amostra. Disponível em: <http://tinyurl. com/s6y0>. Acesso em: 25 out. 2003.

INSTITUTO BRASILEIRO DE GEOGRAFIA E ESTATÍSTICA. Pesquisa industrial - inovação tecnológica 2000b. Acessível em: <http://www.ibge.gov.br/home/estatistica/economia/industria/ pintec>. Acesso em: 18 nov. 2003.
Não se questiona a validade da afirmação de que informação gera conhecimento. Em tese, não há o que discutir. O que não é verdadeiro é que determinado tipo de informação produz necessariamente informação assemelhada, principalmente tratando-se da informação tecnológica. Ao se agregar a informação científica, tecnológica, formal ou informal, ela gera uma tecnologia nova e retorna aos estoques na condição de nova informação para ser (re)utilizada. Essa nova informação pode ter características das anteriores que a geraram ou assemelhar-se mais a um tipo ou a outro. Assim, a hipótese de que patente gera patente não se confirma tendo em vista que as condições exigidas, no contexto atual, inexistem. Repetindo um dos entrevistados: "essa é uma roda que, no Brasil, não roda".

Para ocorrer mudança de cultura, é preciso passar da política e dos discursos que encerram para a fase em que as ações sejam realizadas de forma coordenada na direção de atender a objetivos comuns; isto é, sair da intenção de um discurso de informação para sua real transferência. É estabelecer o diálogo entre a informação tecnológica e seus atores numa relação de informação e conhecimento entre atores e espaços de provisão dos estoques interno e externo, ou seja: promover a interação do conhecimento.

INSTITUTO NACIONAL DE PROPRIEDADE INDUSTRIAL. Relatório de Gestão. Rio de Janeiro, 2002.

MERTON, R.K. The Matthew effect in science II: cumulative advantage and the symbolism of intellectual property. ISIS, n.79, p.606-623, 1988.

SÁBATO, J.; BOTANA, N. La ciência y la tecnología en el desarrollo futuro de América Latina. In: THE WORLD ORDER MODELS CONFERENCE, 1968, Bellagio-Itália. Acessível em: <http://www.cecae.usp.br/tecla/html/sp/html/sp_pg_ info_arti1.html>. Acesso em: 20 set. 2002.

WERSIG, G. Information science: the study of postmodern knowledge usage. Information Processing \& Management, v.29, n.2, p-229-239, 1993.

WERSIG, G.; WINDEL, G. Information science needs a theory of informations actions. Social Science Information Studies, n.5, p.11-23, 1985. 
